\title{
THE "COROLLARIUM II" TO THE PROPOSITION XXIII OF SACCHERI'S EUCLIDES
}

\author{
ALBERT DOU: \\ In memory of Pere Menal
}

\begin{abstract}
This "Corolarium" of the Euclides (1733) contains an original proof of propositions 1.27 and 1.28 of Euclid's Elements. In the same corollary Saccheri explains why he dispenses "not only with the propositions 1.27 and 1.28 , but also with the very propositions 1.16 and 1.17 , except when it is clearly dealt with a triangle circumscribed by alls sides"; and also why he rejects Euclid's proof. Moreover, the corolarium has implications for confirmation of Saccheri's method; and also for his concept of straight line, which leads him to his paralogism of ignorantia elenchi in proposition XXXIII.
\end{abstract}

\section{Introduction}

The Euclides ab omni naevo vindicatus was published in 1733 , the same year of the death of his author Giovanni Girolamo Saccheri. The Euclides is a book of plane geometry in the same sense that the Euclid's Elements are; except that the Euclid's fifth postulate or postulate of parallels is not assumed. We interpret the Elements as Hilbert did in 1899, namely as assuming the postulates or axioms of incidence, order (intermediacy, because of the infinite length of the straight line), congruence, parallels and continuity.

But, in the Euclides, besides to do without the fifth postulate, there is yet another restriction. The purpose of Euclides is precisely to prove the fifth postulate from the other axioms. Since in the Elements the first time that this postulate is applied in the proposition 1.29, it follows that Saccheri could freely assume and apply the first. 28 propositions of book 1. But in the "Preface to the reader" Saccheri writes: 
"[I shall] exchusively dedicate myself to it, that without any 'petitio principii', I prove clearly the controverted Euclidean axiom; to this end I shall dispense not only with the Propositions 27th and 28th of the prior Propositions of Euclid's first Book, but also with the very propositions 16 th or 17 th, except where it is clearly dealt with a triangle circumscribed by all sides" ${ }^{1}$.

The purpose of this present contribution is precisely to explain why Saccheri will work without propositions $27 \mathrm{th}$ and $28 \mathrm{th}$, and even without 1.16 and 1.17 , unless that they are applied to a triangle that is bounded by all sides.

We find the explanation given by Saccheri himself in the Second Corollary to the Proposition XXIII of the Euclides.

The mentioned restriction is not relevant for the main purpose of the Euclides. But it is quite interesting for its own sake. In fact, Saccheri gives a new proof of prop. 1.27 and 1.28 of the Elements, and he does without applying 1.16 in the large. But he is not correct in questioning the soundness of Euclid's proof. His objection is possible because he changes arbitrarily and for the worse the concept of the straight line. Moreover, this second corollary is also interesting because of its implications in the prop. XII-XIV and in the final paralogism of Saccheri in prop. XXXIII of the Euclides. (For a general study of the Euclides, see $[1],[2],[3]$.

\section{Saccheri's proof of prop. 1.27-28 of Euclid's Elements}

Let us recall that propositions 1.16 and 1.17 of the Elements are equivalent, and the latter states that in any triangle $A B C$ we have that ang $A+$ ang $B<2$ rights. In the proof of 1.16 Euclid (tacitly) assumes that the straight line is potentially infinite. In the first 28 propositions of book 1 of the Elements, only the 21 and the 26-28 depend essentially in thcir proofs on prop. 1.16, that is, they depend essentially on the infinite length of the straight line. Saccheri never applics the 21 nor the 26 under the hypothesis of the obtuse angle, and, as we have seen, he explicitly dispenses with 27 and 28 . The reason why Saccheri rejects unconditionally the proposition 1.27 and 1.28 will be given below. Nevertheless all these considerations look rather irrelcvant, since we are interested

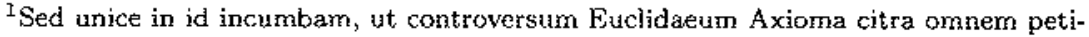
tionem principii clare demonstrem; nunquam idcirco adhibens ex ipsis prioribus Libri primi Euclidaei Propositionibus, non modo vigesimam septimam, aut vigesimam octavam, sed nec ipsas quidem decimam sextam, aut decimam septimam, nisi ubi clarc agatur de triangulo omni ex parte circumscripto. Euc, p. X, XI.
} 
in prop. XXIII, which assumes the hypothesis of the acute angle, and therefore assumes the potentially infinite length of the straight line.

Saccheri has correctly refuted the possibility of the geometry of the obtuse angle in propositions XIII and XIV. From proposition XVII on he will devote himself to the refutation step by step of the hypothesis of the acute angle. The prop. XXII states, figure 26:

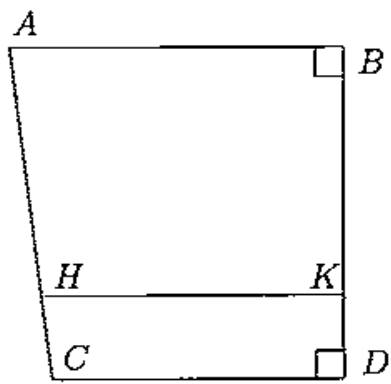

Figure 26

Let $A B$ and $C D$ be perpendicular to $B D$, and let the angles $B A C$ and $D C A$ be both acute. Then, under the hypothesis of the acute angle, the segments $A C$ and $B D$ have a common perpendicular $H K$.

In the next prop. XXIII, figure 27 , he proves:

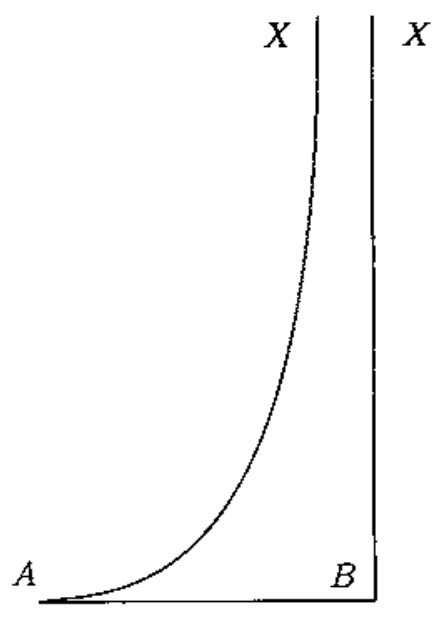

Figure 27

Let $A X$ and $B X$ be two straight lines in the same plane. Then, always in the hpothesis of the acute angle, either they have a common perpendicular, or intersect, or approach each other more and more. 
We note that in this proposition, he does not yet prove that in the last case they must be asymptotic to each other.

Following this proposition there is an irrelevant first corollarium and thereafter follows a scholium. In it Saccheri explains how to construct the common perpendicular to the given straight lines $A X, B X$, Figure 28, when a transversal $P F H D$ is known, such that it makes the internal angles in the same side, which together equal to two rights.

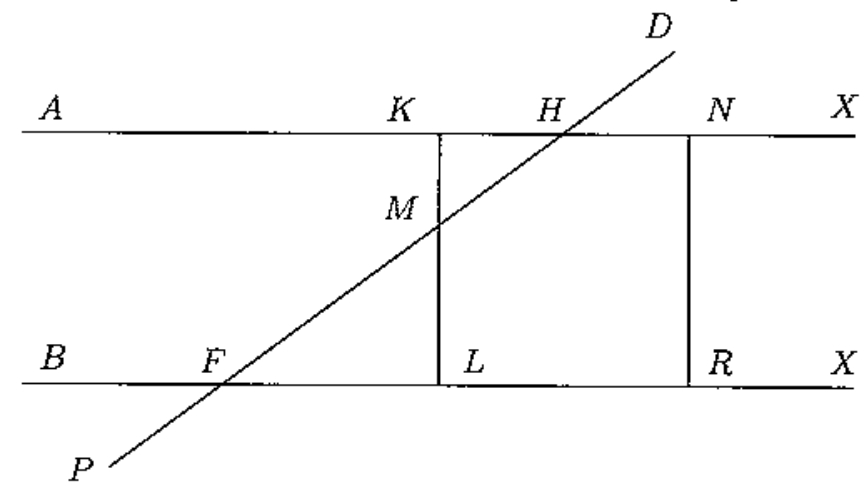

Figure 28

He proves that the common perpendicular $K L$ contains the middle point $M$ of $F H$.

We have next, the second corollary to the proposition XXIII. Saccheri begins this corollary with the conclusion that, if $A X$ and $B X$ have a common perpendicular, then "they can never meet each other, not even at their infinite continuation" 2 . In fact, he proves that they diverge.

Next he writes:

"But, moreover, you have here that the prop. 27th and $28 \mathrm{th}$ of Euclid's first book have been proved; and certainly without immediate dependence on the preceding 16 th and 17 th of the same first book; upon which one could object, in as much as on a finite base one has a triangle with infinite sides; of course to such a triangle would no doubt have recourse, anyone who would hold that such two straights $A X$ and $B X$ met each other at lcast at an infinite distance, although the angles with the transversal PFHD were such as we have assumed." ${ }^{3}$

\footnotetext{
2 "Quod, inquam, illae duae rectae neque ad infinitam earundem productionem coire inter se possint". (EuC, p. 47).

3 "Porro autem demostratas hinc habes Propos. 27 et 28. Libri primi Euclidis; et quidem citra immediatam dependentiam a praecedentibus 16 et 17 ejusdem primi,
} 
In this paragraph Saccheri states that he has correctly proved prop. 1.27 and 1.28; in fact, he had already refuted the hypothesis of the obtuse angle, in figure 28 under the hypothesis of the acute angle $A X$ and $B X$ diverge, and under the hypothesis of the right angle the straights $A X$ and $B X$ with a common perpendicular are obviously equidistant. Therefore they are parallel in the sense of Euclid's definition 23 (Heath 1.154).

Now we recall that Euclid's proof of 1.27 makes use of 1.16. But there is a much greater dependence, since Euclid applies 1.16 in the large, that is, not only to a single triangle, but to a variable triangle, two sides of which may become longer than any prefixed length. Saccheri rightly takes care to state that he has proved the existence of parallels without immediate dependence on 1.16. Much less by application of 1.16 in the large. Taking into account, moreover, what he says in the Preface and we have quoted, it scems that he attaches great importance to this result.

Now, in the second part of the quoted second corollary, Saccheri seems to object that the proof of 1.27 in the Elements is not quite correct. He resorts, in the figure 28 and under the hypothesis of the right angle, to the triangle $F H X$, and doubts that 1.16 could be applied to such a triangle. He considers the point $X$ at infinity of the straight $B F$ as a point of his geometry, let it be the point $X^{*}$, and rejects that 1.16 be applied to the triangle $H F X^{*}$.

I shall argue in 2.b) that, in spite of how strange to us such an interpretation may be, it is the correct interpretation of this quoted text. Here, I remark only that there is in this text no trace of a variable triangle, so that any interpretation referring to an application of 1.16 in the large is to be excluded.

In any case the Saccheri's objection to prop. 1.27 of the Euclid's Elements is unsound. The Euclid's plane, the plane of the Elements, obviously has no point at infinity and therefore the objection has no sense.

The second corollary to the prop. XXIII has yet two more paragraphs. In them Saccheri gives a new proof of the same result, namely that the straights $A X$ and $B X$ can not meet. He argues that, because of the common perpendicular $K L$, if $K X$ and $L X$ meet in the continuation towards the right, then because of an obvious superposition (by a reflection in the common perpendicular $K L$ ), they should meet also in the continuation towards the left, and therefore we could have two straights

circa quas oriri posset diffcultas, quoties sub basi finita infinitilaterum esset triangulum; ad quale nempe triangulum provocare non dubitaret, qui eas duas $A X, B X$ ad infinitam saltern distantiam inter se coituras censeret; quamvis anguli ad incidentem $P F H D$ tales forent, quales supposuimus." (Euc, p. 47-48). 
closing an area. He refers to the fist lemma of prop. XXXII (p. 70), where he proofs that this is not possible.

\section{Implications for prop. XII-XIV and for prop. XXXIII}

a) The second proof just given shows that Saccheri knew the possibility of a reflection in the common perpendicular $K L$, figure 28 . Therefore, it was clear to him, that if two straights such as $K X$ and $L X$ meet to the right, then they had to meet also to the left, and apparently had to closed an area, what is absurd. This fact suggests an interesting observation to the propositions XII-XIV of the Euclides. These three propositions are the decisive ones, in which Saccheri refutes the hypothesis of the obtuse angle. It is worth mentioning that Saccheri never states explicitly the fact that under the hypothesis of the obtuse angle two straight lines necessarily would meet always. The purpose of the present remark is to show that Saccheri had to realize this fact, namely that in the hypothesis of the obtuse angle two straights always meet.

In prop. XII Saccheri proofs: If $A F$ and $P L$ (figure 10) are met by a transversal $A P$ such that $A P L$ is right and $P A F$ is acute, then they will meet.

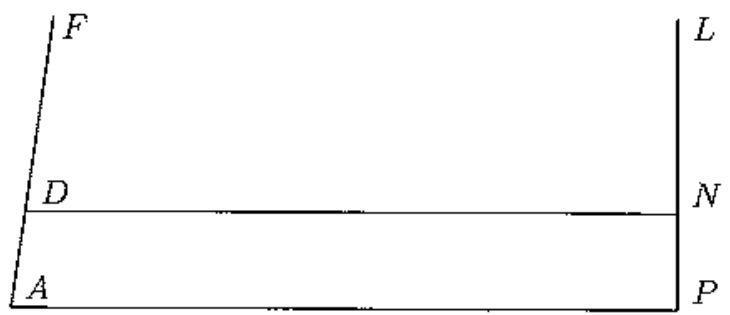

Figure 10

But they obviously will meet even if both angles at $A$ and $P$ are right. In fact, if we take $D$ in $A F$ and drop the perpendicular $D N$ on $P L$, then $D N L$ is right and $N D F$ is acute. Therefore $D F$ an $N L$ meet.

The case is much more obvious from propositions XIII and specially from the sccond proof at prop. XIV. In this last proposition it is obvious also, even without taking into account the reflection in the common perpendicular, that, in the hypothesis of the obtuse angle, if two straights meet to the right, they must meet to the left.

It seems correct to conclude that Saccheri had realized that, under the hypothesis of the obtuse angle; two straights always meet. Because of prop. XIV and because of the reflection in the common perpendicular he 
realized also, that apparently any two straight lines had to meet in two points. Of course neither Saccheri nor Taurinus (1826) could imagino that dropping the postulate of the infinite length of the straight line, the two points could be or had to be the same point and the resulting plane was not orientable; that is to say, there could be a new geometry as good as the Euclidean one of the Elements.

Finally, why Saccheri did never statc explicitly that in the hypothesis of the obtuse angle two straights always meet? Most likely because of his extreme attachment to this method of proof. He wanted to proof, in any hypothesis, the fifth postulate and just that. That is what he did in the proposition XIII in the hypothesis of the right or obtuse angles. As a confirmation I refer to the statements of the proposition XIV, XXXVIII and XXXIX; and specially to his own words in the central part (p. 99) of the Scholion with which he finishes the first book of the Euclides.

b) It is precisely in the second corollary of prop. XXIII that Saccheri for the first time in the Euclides uses the term "point $X$ " to designate a point on a certain straight line $B L$ "at least at an infinite distance" of both $B$ and $L$, or equivalently a point $X$ lying at the infinite of $B L$. Not only the words Saccheri uses, but also for the sake of the argument it appears that he assumes the existence of the point $X$ as a point of the plane.

Such a term or an equivalent one is used also in the second corollary to prop. XXV (p. 55) and in the statements of prop. XXVI, XXVII and XXXII (p. 55, 57,68).

Perhaps in these quotations or at least in some of them the term "point $X$ " may be understood as an ideal point, not an ordinary point; or even as an informal way of speech. But certainly this is not the case with prop. XXXIII, where Saccheri thinks that he has definitively refuted the hypothesis of the acutc angle. After five long lemmas he very laboriously misproves that there are "two straights $A X$ and $B X$ existing in the same plane, which continued towards the points $X$ to infinity must at length run together into just one straight line, receiving in fact in just one infinitely distant point $X$ a common perpendicular in the same plane with them". ${ }^{4}$

Kepler and Desargues had much earlier introduced points at infinity. Saccheri, in his Logica demonstrativa does not concede the existence of a created being actually infinite; much less the existence of an infinitc

\footnotetext{
4"duas in eodem plano existentes rectas $A X, B X$, quae in infinitum protactae versus eas partes punctorum $X$ in unam tandem eandemque rectam lineam coire debeant, nimirum recipiendo, in uno codemque infinite dissito puncto $X$, commune in eodem com ipsis plano perpendiculum" (p. 70; see p. 86).
} 
being, limited at both ends; but he argues that the arguments taken from the geometry are not convincing (Log. D., thesis 19, p. 273). Therefore, he sees no contradiction in the concept of an infinite straight line, limited at both ends. (See [6, p. 372-373]).

Of course it is quite understandable that Saccheri runs in a contradiction, because assuming ordinary points at infinity the axioms of congruence can not be fulfilled. But, then, he is dealing no more with the axioms of the geometry of the Euclid's Elements. In fact, his paralogism is based on the fallacy of ignorantio elenchi.

\section{References}

1. A. Dou, Logical and historical remarks on Saccheri's Geometry, Notre Dame J. Formal Logic 10 (1970), 385-415.

2. A. Dou, De la verdad a la validez en Geometria (1733-1871), Pensamiento 28 (1972), 413-429.

3. A. Dou, Orígenes de la geometría no cuclidiana: Saccheri, Lambert y Taurinus. In "Historia de las Matemáticas en el siglo XIX", Real Academia de Ciencias, Madrid, 1992.

4. EUCLIDES, " $\Sigma \tau o \iota \chi \varepsilon \iota \alpha$ (Elements)," critical edition and translation into latin by I. L Heiberg. English translation by T. L. Heath, Dover, New York, 1956, (2 ${ }^{\text {nd }}$ ed. $)$.

5. D. HilberT, "Grundlagen der Geometrie," Teubner, Leipzig, 1899.

6. J.C. PONT, "L'aventure des parallèles. Histoire de la géométrie non euclidienne: précurseurs et attardés," Peter Lang, Berne, 1986.

7. G. SACCHerI, "Logica demostrativa," Turin, 1697. Photoreproduced by Georg Olms Verlag, Hildeshcim-iNew York, 1980.

8. G. SACCHERI, "Euclides ab omni naevo vindicatus: sive conatus geometricus quo stabiliuntur Prima ipsa universae Geometriae Principia," Milan, 1733. Translated into English by G. B. Halsted, "Euclides vindicatus", Chelsea Publishing Company, New York, 1986 ( $2^{\text {nd }}$ ed.).

Departament de Matemàtiques

Universitat Autònoma de Barcelona

08193 Bellaterra (Barcelona)

SPAIN

Rebut el 7 de Gener de 1992 